Cmail . inntalofain alariddin anid

\title{
RANCANG BANGUN SISTEM KONTROL ROBOT INTAI TEMPUR BERBASIS SMARTPHONE ANDROID
}

\author{
GINANJAR ${ }^{1}$, NURACHMAN SUPADMANA MUDA ${ }^{1}$, EKO KUNCORO \\ Progam Studi Telekomunikasi Militer \\ Jurusan Telekomunikasi Politeknik Angkatan Darat \\ Jl. Kesatrian Pusdik Arhanud, Kota Batu 65324 \\ E-mail: kommil2507@,gmail.com
}

\begin{abstract}
ABSTRAK
sebuah robot intai tempur yang dapat dikontrol dari jarak jauh, dengan berbasis Smartphone Android melalui jaringan Wi-Fi Smartphone Andoid yang dilengkapi sebuah kamera untuk pengintaian guna mendapatkan data sasaran musuh secara realtime di sekitar robot kemudian di tampilkan pada aplikasi Smartphone Android. Robot ini menyerupai bentuk mobile robot yang dapat bergerak kesegala arah, dengan mengimplementasikan metode kontrol PID pada robot intai tempur dapat menghasilkan output realtime yang tinggi dan error yang kecil, dan mengoptimasikan sistem pengatur pergerakan motor yang meliputi waktu respon dan jarak kontrol robot intai tempur. Karena robot ini dapat di kontrol dari jarak jauh menggunakan Smartphone Android, maka sangat cocok digunakan untuk pengintaian dalam tugas militer untuk mengurangi resiko dan bahaya secara langsung yang dapat merenggut korban jiwa dan materil.
\end{abstract}

Kata kunci: Smartphone Android, Kamera, Mobile Robot, Realtime

\section{PENDAHULUAN}

Intai Tempur (Taipur) adalah pasukan berkualifikasi intelijen tempur Komando Strategis Angkatan Darat (KOSTRAD). Prajurit Taipur Kostrad harus memiliki kemampuan khusus di dalam melaksanakan tugas pokoknya seperti operasi lawan gerilya, pertempuran pemukiman, perkotaan, pertempuran jarak dekat, tugas intelijen Sandhi Yudha serta intelijen tempur aspek laut selain memiliki kemampuan tempur khusus juga dilengkapi dengan peralatan tempur khusus, seperti kendaraan tempur, Helm anti peluru, Rompi anti peluru (Body Protector), alat selam tempur close circuit, kendaraan bawah air, dan berbagai jenis senjata canggih lainnya.

Dalam menjalankan tugas yang diembannya, beberapa medan berbahaya yang tidak memungkinkan prajurit untuk melanjutkan tugasnya, seperti medan terbuka, bahaya garis, ketinggian. Sehingga membuat gerak maju prajurit terhambat yang dapat 
merenggut korban jiwa dan materil. Untuk mengurangi resiko dan bahaya secara langsung, maka diperlukan suatu alat yang dapat menggantikan kehadiran prajurit pada medan tersebut. Peralatan tersebut diharapkan dapat mewakili peran prajurit pada medan yang dimaksud yaitu dapat memberikan informasi dari suatu tempat sasaran ke prajurit taipur dengan jarak jauh. Dengan demikian akan lebih menjamin keberhasilan prajurit, informasi yang diperlukan dari suatu tempat sasaran tetap bisa didapatkan dan dipantau secara berkelanjutan. Salah satu solusi untuk mencegah hal tersebut di atas yaitu dengan mengembangkan unmanned vehicle untuk keperluan pengintaian yang salah satunya diwujudkan dalam bentuk robot intai tempur. Robot adalah sistem mekanik yang mempunyai fungsi gerak analog untuk fungsi gerak organisme hidup, atau kombinasi dari banyak fungsi gerak dengan fungsi intelligent, yang dapat melakukan tugas fisik, baik menggunakan pengawasan dan kontrol manusia, ataupun menggunakan program yang telah didefinisikan terlebih dulu seperti kecerdasan buatan Robot yang dilengkapi dengan peralatan komunikasi dimungkinkan untuk dikendalikan dari jarak jauh serta memungkinkan untuk melakukan pengiriman informasi dari suatu tempat sasaran ke prajurit Taipur.

Perkembangan teknologi robot yang dapat dikembangkan melalui jaringan internet menggunakan perangkat smartphone Android. Seperti yang diketahui bahwa masyarakat saat ini dengan mudah mengakses sesuatu diinternet dengan menggunakan perangkat smartphone Android. Maka dari itu peneliti ingin mengembangkan Robot Intai Tempur dengan sistem kontrol smartphone Android yang dengan mudah dapat diakses ataupun dikontrol dari jarak jauh. Hal tersebut juga diungkapkan oleh Asep Saefullh dkk bahwa dengan berkembangnya teknologi seluler yang tidak hanya digunakan sebagai telephone dan SMS saja, tapi juga dapat digunakan sebagai perangkat untuk mengendalikan sebuah robot, seperti halnya smartphone Android yang sudah ditanamkan fitur komputer. Sehingga teknologi robot bisa dikendalikan jarak jauh dan sesuai yang diinginkan pengguna. Salah satu peralatan yang dikontrol berupa sebuah robot yang dilengkapi dengan kamera untuk keperluan pengintaian sehingga operator tetap dapat mengendalikan robot tanpa harus melihat posisi robot. Selain itu, perangkat smartphone Android saat ini relatif mudah didapat dan harganya cukup terjangkau serta 
mudah untuk dilakukan pengembangan jaringan.

\section{METODE PENELITIAN}

Metode penelitian dilaksanakan dengan tujuan untuk meneliti, merancang dan mengembangkan suatu rangkaian dasar dengan mempertimbangkan segi kualitas dalam proses perancangan robot intai tempur yang digunakan untuk mengintai secara realtime dengan memanfaatkan kamera sebagai monitoring keadaan. Sedangkan pemilihan komponen pokok adalah untuk memperoleh hasil yang diinginkan dari rangkaian yang dibuat sehingga dapat beroperasi sesuai dengan yang diharapkan.

\section{Perancangan alat}

Perancangan alat terdiri dari perencangan perangkat keras (hardware) dan perangkat lunak (software). Perancangan hardware meliputi perancangan dan perakitan. Sedangkan perancangan software yaitu merencanakan flowchart supaya alur pikir tentang software yang digunakan berjalan sesuai yang diharapkan. Dari perencanaan dan perancangan alat tersebut digambarkan pada blok diagram pada Gambar1.

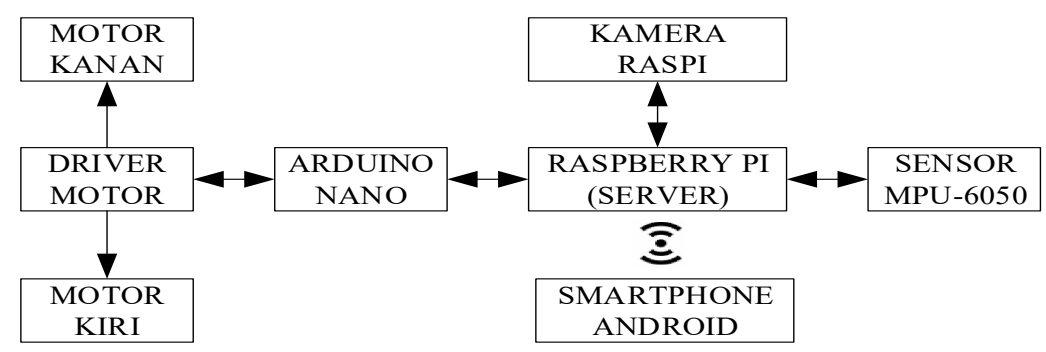

Gambar 1. Diagram Blok Komunikasi Data

Gambar 1. dapat diketahui sistem kerja dari alat yaitu sebagai berikut:

a. Raspberry Pi sebagai pusat kendali robot menerima input dari kamera dan perintah dari user. Berdasarkan perintah dari user, Raspberry pi akan memberikan sinyal output untuk Arduino Nano. Raspberry Pi juga sebagai server yang berfungsi sebagai perangkat yang melalui jaringan internet dengan antarmuka aplikasi berbasis Smartphone Android yang dibenamkan pada Raspberry pi yang langsung terintegrasi dengan robot yang sekaligus berfungsi sebagai server.

b. Kamera digunakan sebagai kamera navigasi bagi operator untuk mengontrol robot. Hasil visualisasi dari kamera akan ditampilkan secara real time pada aplikasi Android. 
c. Smartphone Android digunakan sebagai user (operator) yang bersifat fleksibel yang tidak terbatas. Operator cukup mengakses aplikasi untuk mengendalikan robot. Raspberry Pi sebagai pusat kendali robot menerima input dari camera dan perintah dari user.

e. Arduino Nano untuk mengakses Driver motor menggunakan PWM (Pulsa Witdh Mudulation).

f. Driver motor untuk mengendalikan motor kiri dan kanan.

\section{2. perancangan Perangkat Keras}

Perancangan alat berupa perangkat keras (hardware) adalah perancangan desain seperti yang ditunjukkan pada Gambar 2.

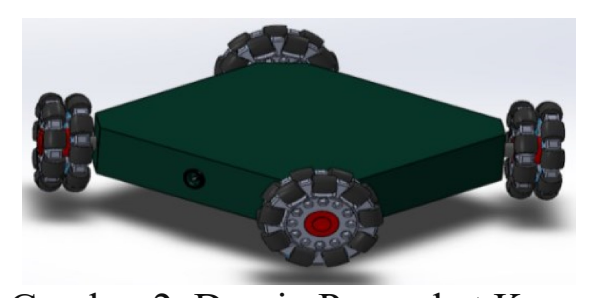

Gambar 2. Desain Perangkat Keras

Gambar 2 adalah perencanaan desain perangkat keras intai tempur dengan pengontrolan melalui Smartphone Android dan monitoring realtime video.

\section{Perancangan Perangkat Lunak}

Perancangan perangkat lunak adalah perancangan bahasa program yang akan dimasukkan atau ditanamkan pada robot Intai Tempur. Software (bahasa program) yang akan diprogram dalam smartphone Android. Dalam bentuk aplikasi sehingga dapat berjalan sesuai dengan perencanaan perancangan yang telah direncanakan. Pada Gambar 3 dijelaskan dijelaskan diagram alir pada sistem kontrol sedangkan Gambar 4 dijelaskan diagram alir penerima pada robot Intai Tempur. 


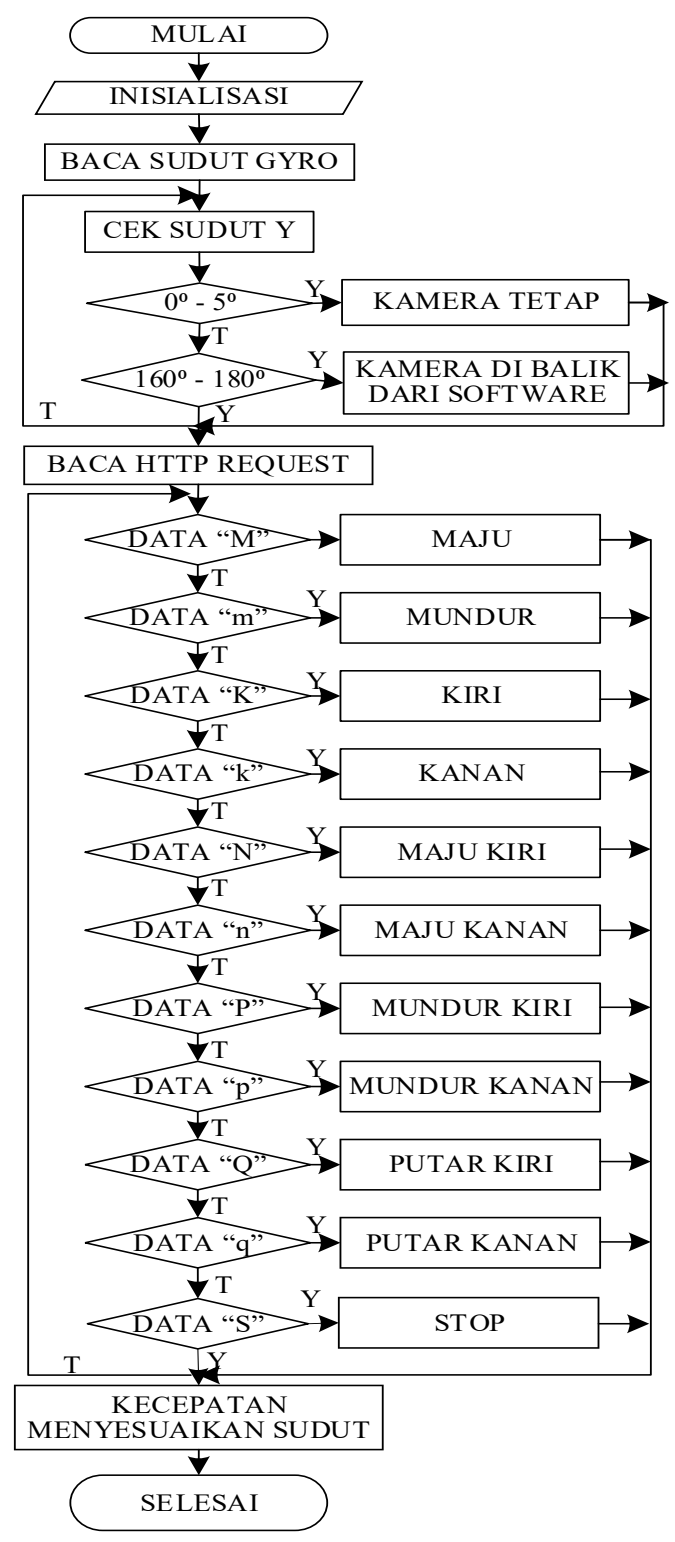

Gambar 3. Diagram Alir pada Kontrol Robot Intai Tempur

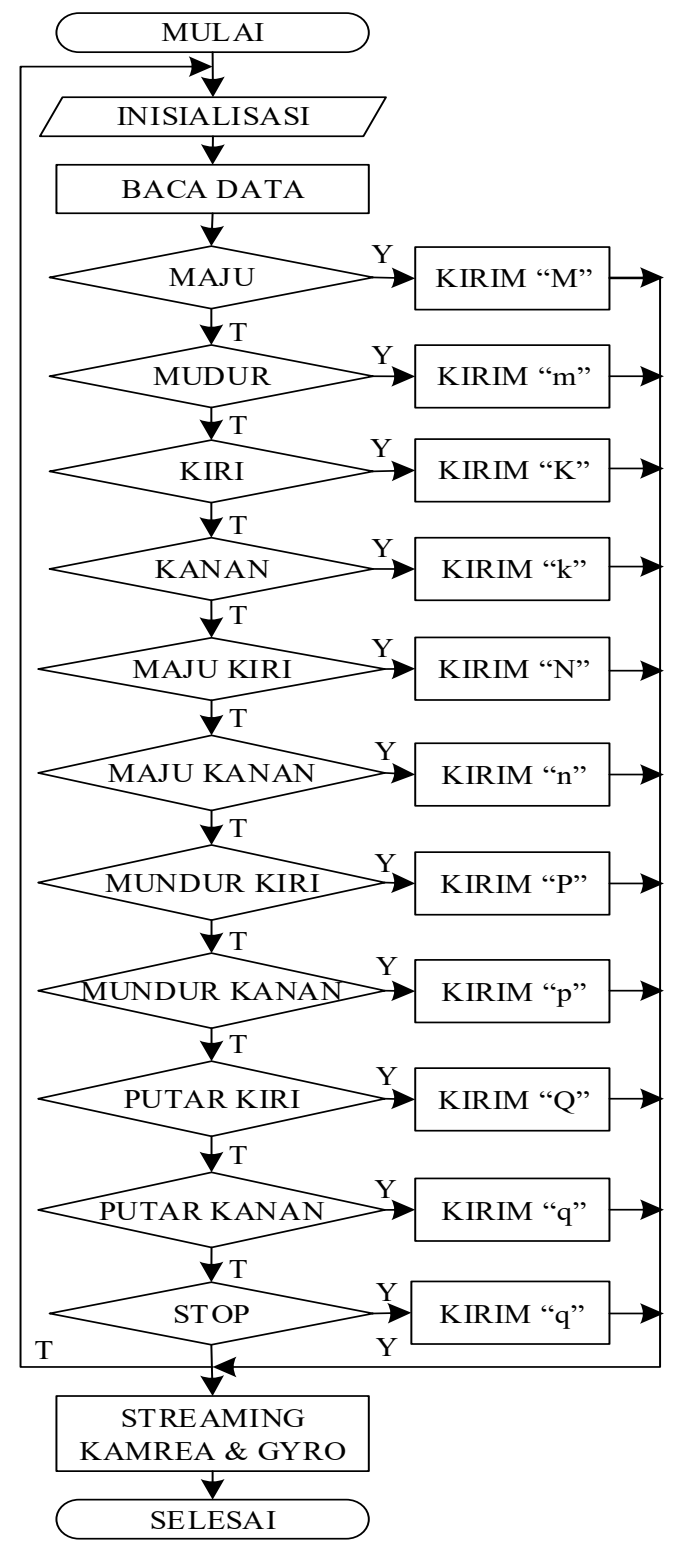

Gambar 4. Diagram Alir Pada Robot| Intai Tempur

\section{HASIL DAN PEMBAHASAN}

Dalam bab ini akan dibahas tentang hasil pengujian dan pembahasan alat yang telah dibuat berdasarkan perancangan sistem yang telah dibuat. Pengujian alat dilaksanakan untuk mengetahui kinerja dari sistem dan untuk mengetahui apakah sudah sesuai dengan perancangan atau belum. Adapun hasil dari perancangan dan pembuatan 


\section{JURNAL INSTEK |NFORMATKASANS DAN TEKNOLOG|}

robot tersebut dapat dilihat pada Gambar 5 .

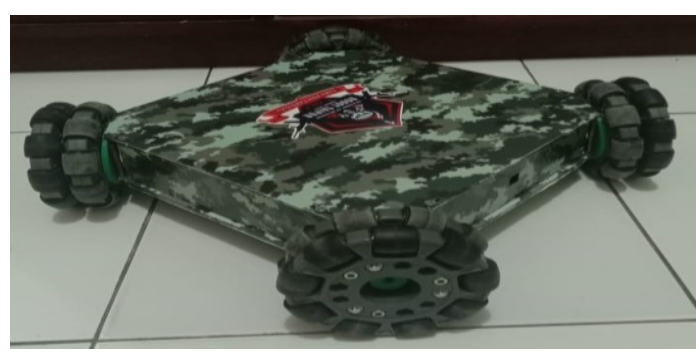

Gambar 5. Hasil Akhir Pembuatan Robot Intai Tempur

\section{Hasil Pengujian PID}

Tujuan pengujian Proportional Integral Derivatif (PID) dilakukan untuk mengetahui apakan rumusan yang digunakan dalam pembuatan kendali PID dapat berjalan sesuai yang diharapkan. penentuan nilai parameter P, I dan D menggunakan metode heuristik dalam mencari nilai kp, ki, dan kd dengan patokan mencari system yang inginkan untuk pedoman dalam memberikan nilai $\mathrm{kp}, \mathrm{kd}$, dan hasil nilai PID setelah dimasukan di Simulink. Respon penalaan parameter kontrol PID sistem pengontrolan kecepatan motor DC. Set point adalah variabel yang dikehendaki dan sebuah kontroler akan selalu menyamakan kontroler variabel dengan set point. Penulis menentukan nilai set point 255 agar pada saat membaca grafik lebih mudah. dapat dilihat pada tabel 1 .

\begin{tabular}{|c|c|c|c|c|c|c|}
\hline Set Point & \multicolumn{3}{|c|}{ PID } & $\begin{array}{l}\text { Settling } \\
\text { Time }\end{array}$ & $\begin{array}{l}\text { Rise } \\
\text { Time }\end{array}$ & \multirow{2}{*}{$\begin{array}{l}\text { Peak } \\
\text { error }\end{array}$} \\
\hline \multirow{16}{*}{255} & $\mathrm{Kp}$ & $\mathrm{Ki}$ & $\mathrm{Kd}$ & Detik & Detik & \\
\hline & 350 & 300 & 50 & 1.21 & 6.79 & $>=1$ \\
\hline & 1.1 & 0.1 & 3.7 & 1.63 & 9.17 & 1.99 \\
\hline & 1.1 & $\mathrm{O}$ & $\mathrm{O}$ & 1.27 & 0.003 & 1.96 \\
\hline & 1.5 & $\mathrm{O}$ & $\mathrm{O}$ & 1.27 & 0.003 & 1.97 \\
\hline & 2 & $\mathrm{O}$ & $\mathrm{O}$ & 1.27 & 0.002 & 1.97 \\
\hline & 2 & 0.6 & $\mathrm{O}$ & 1.33 & 0.002 & 1.97 \\
\hline & 2 & 1.1 & $\mathrm{O}$ & 1.4 & 0.002 & 1.98 \\
\hline & 2 & 1.4 & $\mathrm{O}$ & 1.43 & 0.002 & 1.98 \\
\hline & 2 & 2 & $\mathrm{O}$ & 1.52 & 0.002 & 1.98 \\
\hline & 2 & 2 & 0.01 & 0.01 & 0.02 & 1.15 \\
\hline & 2 & $\mathrm{O}$ & 1.8 & 3.35 & 1.88 & $>=1$ \\
\hline & 2 & $\mathrm{O}$ & 2.9 & 2.08 & 1.17 & $>=1$ \\
\hline & 2 & 0.1 & 0.1 & 0.0005 & 0.0003 & $>=0.9$ \\
\hline & 2 & 0.3 & 1.4 & 4.32 & 2.42 & $>=1$ \\
\hline & 2 & $\mathrm{O}$ & 0.6 & 0.0001 & 5.65 & $>=1$ \\
\hline
\end{tabular}

Tabel 1. terlihat bahwa ketika kontroler $\mathrm{PID} \mathrm{Kp}=2, \mathrm{Ki}=2$ dan $\mathrm{Kd}=0.01$ diberi gangguan berupa kelebihan tegangan, maka kecepatan motor DC untuk mencapai set 
point terbukti tidak mengalami penurunan atau kenaikan yang signifikan. Kecepatan motor masih tetap konstan mengikuti set point yang diinginkan dan parameter yang dihasilkan tidak berubah saat diberi gangguan Settling Time $0.01 \mathrm{~s}$, Rise Time $0.02 \mathrm{~s}$, dan pada peak 1.15. Dengan Rangkaian pada simulink seperti gambar 6. dengan nilai $\mathrm{kp}=2$, $\mathrm{ki}=2$ dan $\mathrm{kd}=0.01$.

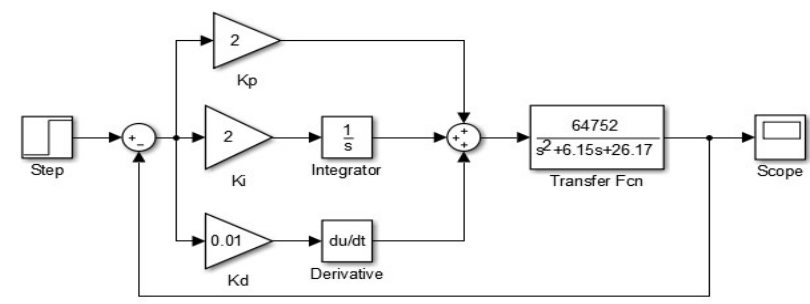

Gambar 6. Rangkaian Kontrol PID

Grafik yang dihasilkan dari pengujian sistem seperti pada gambar 7 .

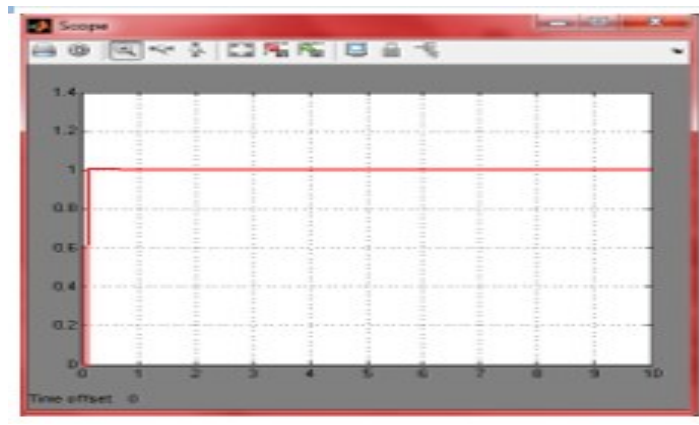

Gambar 7. Respon Sistem dengan Kontrol PID

\section{Hasil Pengujian PWM}

Pengujian motor DC dilakukan dengan mengukur kecepatan putar motor pada nilai PWM yang berbeda dari masing-masing roda omni robot dengan menerapkan metode PID. Pengukuran kecepatan putar motor DC diukur dengan menggunakan alat digital tachometer dan ditunjukkan dalam satuan rpm (revolutions per minute). Hasil pengujian motor DC ditunjukkan pada Tabel 2. 


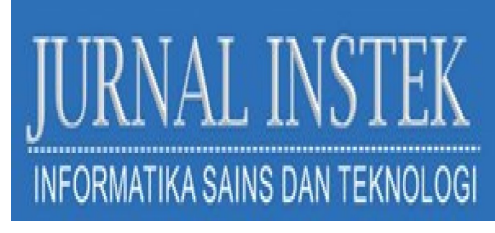

Volume 5 Nomor. 1, April 2020

P-ISSN : 2541-1179, E-ISSN : 2581-1711

Ojs :http://journal.uin-alauddin.ac.id/index.php/instek/index

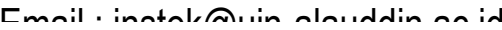

Tabel 2. Hasil penguijan kontrol motor.

\begin{tabular}{|c|c|c|c|c|c|}
\hline \multirow{2}{*}{ Pergerakan } & \multirow{2}{*}{ PWM } & \multicolumn{4}{|c|}{ RPM (tachometer) } \\
\hline & & MI & M2 & MI3 & M4 \\
\hline \multirow{5}{*}{ Maiu } & 100 & 188.4 & 188.9 & 188.1 & 188.2 \\
\hline & 150 & 239.6 & 239.3 & 239.8 & 239.9 \\
\hline & 200 & 266.8 & 266.5 & 266.3 & 266.6 \\
\hline & 250 & 295.8 & 295.3 & 295.7 & 295.3 \\
\hline & 255 & 298.2 & 298.8 & 298.5 & 298.3 \\
\hline \multirow{5}{*}{ Mundur } & 100 & 188.7 & 188.5 & 188.3 & 188.9 \\
\hline & 150 & 239.4 & 239.8 & 239.1 & 239.5 \\
\hline & 200 & 266.9 & 266.5 & 266.7 & 266.3 \\
\hline & 250 & 295.3 & 295.5 & 295.9 & 295.7 \\
\hline & 255 & 298.9 & 298.3 & 298.6 & 29.1 \\
\hline \multirow{5}{*}{ Kiri } & 100 & 188.8 & 188.2 & 188.7 & 188.6 \\
\hline & 150 & 239.6 & 239.3 & 239.0 & 239.7 \\
\hline & 200 & 266.8 & 266.9 & 266.5 & 266.3 \\
\hline & 250 & 295.3 & 295.8 & 295.5 & 295.1 \\
\hline & 255 & 298.7 & 298.2 & 298.6 & 298.5 \\
\hline \multirow{5}{*}{ Kanan } & 100 & 188.7 & 188.5 & 188.4 & 188.3 \\
\hline & 150 & 239.9 & 239.5 & 239.8 & 239.6 \\
\hline & 200 & 266.5 & 266.2 & 266.8 & 266.6 \\
\hline & 250 & 295.2 & 295.8 & 295.3 & 295.5 \\
\hline & 255 & 298.3 & 298.9 & 298.6 & 298.2 \\
\hline
\end{tabular}

Pengujian kontrol motor DC untuk mendapatkan kontrol arah putar motor sesuai dengan arah putar motor yang diharapkan. Kecepatan putar motor hampir sama untuk nilai PWM yang sama, dan memiliki kecepatan putar yang semakin tinggi dengan nilai absolut dari PWM yang semakin besar

\section{Hasil Pengujian Time Respon}

Tujuan pengujian Time respon pada komunikasi data Android dengan robot adalah untuk mengetahui kecepatan data yang dikirimkan setiap bit per detik.

\section{Hasil Pengujian Kamera sebagai monitoring}

Tujuan Pengujian kamera untuk memonitoring keadaan sekitar robot secara realtime. Pengujian kamera dilakukan mulai dari menyambungkan kamera ke perangkat Raspberry Pi sampai kamera dapat menangkap video sehingga dapat ditampilkan pada halaman aplikasi smartphone Android. 
Cmail . inntal, Aarin olnuiddin on id

Tabel 3. Pengujian Time Respon tanpa Penghalang

\begin{tabular}{c|c|c|c|c|c|c|c|}
\hline \multirow{2}{*}{ No } & \multirow{2}{*}{ Jarak $(\mathrm{m})$} & \multicolumn{7}{|c|}{ Time Respon (ms) } \\
\cline { 3 - 8 } & 10 & 1 & 2 & 3 & 4 & 5 & Rata-Rata \\
\hline 1 & 10 & 0.32 & 0.14 & 0.25 & 0.34 & 0.13 & 0.23 \\
\hline 2 & 20 & 0.23 & 0.36 & 0.59 & 0.43 & 0.63 & 0.47 \\
\hline 3 & 30 & 1.28 & 0.43 & 0.31 & 1.09 & 1.05 & 0.83 \\
\hline 4 & 40 & 1.47 & 1.69 & 2.35 & 1.81 & 1.59 & 1.78 \\
\hline 5 & 50 & 2.59 & 2.46 & 2.37 & 2.79 & 3.36 & 2.71 \\
\hline 6 & 60 & 3.56 & 4.44 & 3.54 & 4.42 & 3.51 & 3.89 \\
\hline 7 & 70 & 5.37 & 5.46 & 4.72 & 6.45 & 5.81 & 5.56 \\
\hline 8 & 80 & 9.79 & 9.57 & 9.59 & 9.37 & 9.67 & 9.60 \\
\hline
\end{tabular}

本

Tabel 4. Pengujian Time Respon dengan Penghalang

\begin{tabular}{c|c|c|c|c|c|c|c|}
\hline \multirow{2}{*}{ No } & \multirow{2}{*}{$\operatorname{Jarak}(\mathrm{m})$} & \multicolumn{6}{|c|}{ Time Respon (ms) } \\
\cline { 3 - 8 } & 5 & 1 & 2 & 3 & 4 & 5 & Rata-Rata \\
\hline 1 & 10 & 0.36 & 0.41 & 0.59 & 0.32 & 0.29 & 0.19 \\
\hline 2 & 15 & 0.56 & 0.76 & 0.62 & 0.81 & 1.08 & 0.44 \\
\hline 3 & 20 & 1.48 & 1.94 & 1.63 & 1.79 & 1.91 & 1.75 \\
\hline 4 & 25 & 2.94 & 2.89 & 2.41 & 2.32 & 2.15 & 2.54 \\
\hline 5 & 25 & 4.07 & 4.55 & 3.87 & 4.21 & 3.91 & 4.12 \\
\hline 6 & 30 &
\end{tabular}

\section{Hasil Pengujian Kamera sebagai monitoring}

Tujuan Pengujian kamera untuk memonitoring keadaan sekitar robot secara realtime. Pengujian kamera dilakukan mulai dari menyambungkan kamera ke perangkat Raspberry Pi sampai kamera dapat menangkap video sehingga dapat ditampilkan pada halaman aplikasi smartphone Android.

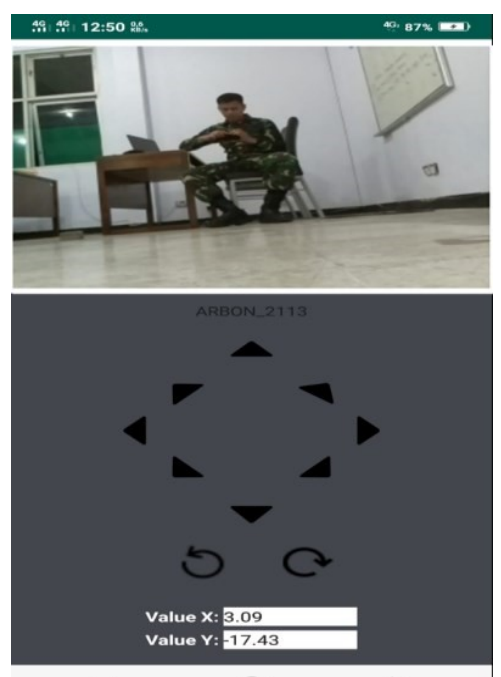

Gambar 8. Monitor Smartphone Android pada saat menangkap gambar 


\section{KESIMPULAN}

Hasil perencanaan, pembuatan dan pengujian apliasi, maka dapat ditarik beberapa kesimpulan. Kesimpulan-kesimpilan tersebut antara lain:

1. Arah dan kecepatan pergerakan motor dapat dikontrol menggunakan sinyal PWM yang lebar pulsanya diperoleh dari perhitungan nilai PID Untuk menjaga kestabilan kecepatan putar motor pada robot, kendali PID telah diterapkan. Untuk robot yang dirancang dalam penelitian ini, nilai $\mathrm{Kp}, \mathrm{Ki}$ dan $\mathrm{Kd}$ yang sesuai adalah $\mathrm{Kp}=2, \mathrm{Ki}=2$, $\mathrm{Kd}=0.01$.

2. Dalam alat ini perancangan robot di buat menggunakan komunikasi wireless $\mathrm{Wi}-\mathrm{Fi}$ smartphone Android dengan Raspberry Pi 3B pada robot dengan waktu respon rata-rata $3.1 \mathrm{~ms}$ sampai jarak 80 meter tanpa penghalang dan waktu respon rata-rata $1.6 \mathrm{~ms}$ sampai jarak 30 meter dengan penghalang. Kecepatan tanggap dari Raspberry Pi dipengaruhi oleh jarak serta halangan dan kekuatan sinyal dari $W i-F i$ yang digunakan, semakin baik kualitas dari Wi-Fi maka semakin jauh jarak koneksi untuk melakukan pengiriman pengiriman ke Raspberry Pi.

3. Monitoring kamera pengintai dari jarak pada saat menangkap gambar video yang di tampilkan pada halaman aplikasi smartphone Android berupa streaming video secara real time Kelancaran video streaming sangat tergantung pada kelancaran jaringan internet yang digunakan

\section{DAFTAR PUSTAKA}

Rahmayadi Edi. 2015. Pengintai Tempur TNI Punya Kemampuan Operasi di Segala Medan. Di Ambil Dari: HTTPS ://m.cnnindonesia.com /nasional/20151114234900-20-91697.Diunduh tanggal 1 November 2019

Lubis, Zulkarnain. 2018. Metode Baru Robot Pengantar Menu Makanan Menggunakan Android dengan Kendali PID Berbasis Mikrokontroler. Journal of Electrical Technology.Vol. 3, No. 2. Hal 105-115. Institut Teknologi Medan.

Samudera, Nandana Adya. 2015. Perancangan Sistem Keamanan Ruangan Menggunakan Rasberry Pi. Jurnal e-Proceeding of Engineering: Vol. 2, No 2. Hal 3743-3754. Fakultas Teknik Elektro. Universitas Telkom Bandung. 